\title{
The Right to Privacy, The New Media and Human Development in Nigeria
}

\section{Ben U Nwanne*}

Department of Mass Communication, Delta State University, P.M.B 1, Abraka, Nigeria

\begin{abstract}
This paper examines the right to privacy, the new media and national development efforts in Nigeria. It draws attention to the need to be ethical in using the new media of communication which have practically made the world a "global village" as previously predicted by media iconoclast and scholar, Marshal McLuhan. The social responsibility theory of the press provides theoretical anchor for the paper. This paper which depends on secondary data, identifies some new media to include the electronic mail (e-mail), Internet, GSM, videoconferencing and others. Depending on the constitution $f$ the Federal Republic of Nigeria and the Code of Ethics for Nigerian Journalists, the author makes a robust case for the protection of the privacy of the individual to enable him/her contributes meaningfully to national development efforts. Some cases on the invasion of peoples privacy have been highlighted especially the Sir Keith Rupert Murdoch incident in England, the Anita Hagan Bassey and Oge Okoye cases in Nigeria. It has also been noted that certain factors tend to limit the use of he new media in Nigeria, such as poor power situation, high costs, lack of adequate knowledge and skill as many persons, including journalists, do not make themselves available for instruction and training. In order to improve the use of the new media in a professional and responsible manner, it is recommended among others, that computer education should be given institutional and government attention, media houses should show more interest than they are doing at the moment in handling issues related to ICT while ethical orientation should be given more attention than it is receiving at the moment by all concerned.
\end{abstract}

Keywords: Human development; Human communication; National development; Media laws

\section{Introduction}

There is an explosion in human communication in ways previously thought impossible. At the click of a bottom messages are sent across thousands of kilometers around the globe. Indeed, the reality of the global village, which media Iconoclast and thinker Marshal McLuhan predicted decades earlier, is here with us. This has been made possible by the invention of electric gadgets especially the internet which has become a phenomenon. Its efficiency is matched by its phenomenal growth. According to Amaobi [1] ownership and usage of the new media among young people in Nigeria has increased substantially although, she acknowledged that there was still a wide gulf between internet usage between the youths in the United States of America and their counterparts in Nigeria.

But this is understandable given the situation in the developing countries, including Nigeria, where infrastructural inadequacy remains a major challenge. For no justifiable reasons, especially for an oil-rich country, Nigeria's infrastructures (if you wish to describe it as such) are either in a terrible state or simply non-existent. For instance, despite the billions of Dollars spent on the improvement of the power sector, especially during the eight year rule of Olusegun Obasanjo, Nigeria still gropes in the dark. A few hours of uninterrupted power supply is celebrated in Nigeria. Beyond rhetorics, the problem persists and there seems to be no end in sight to the problem as the country generates less than 4,000 Mega Watts currently.

Research findings suggest that internet penetration is quite high in Nigeria, the highest in Africa. According to a Vanguard online report [2], the Global Director for Technology and Emerging Markets James Fergusson: Internet Usage is now driven by mobile phones. Mr. Fergusson further stated that among online users digital is the primary media channel at $61 \%$.

The poor or non-existent electricity power in many parts of the country has far-reaching implications for access and use of the new media. This is worsened, of course, by the teeming population of urban and rural poor who see the acquisition of the instruments of the new media as waste of resources. Again, the situation is further worsened by the large pool of illiterate persons in Nigeria which is by far the most populated black nation on earth. In fact, Ethiopia which is the second largest populated country with 85 million in Africa, is about half the population of Nigeria. Despite the challenges highlighted, many are struggling to be part of the global village by accessing and using the new media. In doing this, it is imperative that certain legal and ethical considerations are embraced. There is need therefore for the recognition and protection of the privacy of the individual.

\section{Definition of Terms}

In order to attain a measure of conceptual and operational clarity, it is germane to define the following terms: media laws, new media and development.

\section{Media laws}

Media laws refer the legal framework under which journalists operate in any given environment' [3]. The political authority in any country, through its legislative arm, is empowered to make laws for the smooth and orderly administration of that state. The philosophy of the government in power invariably affects the kind of laws it churns out,

*Corresponding author: Ben U Nwanne, Department Of Mass Communication, Delta State University, P.M.B 1, Abraka, Nigeria, Tel: 08033038431; E-mail: bennwanne2@gmail.com

Received July 01, 2014; Accepted September 23, 2014; Published September 30,2014

Citation: Nwanne BU (2014) The Right to Privacy, The New Media and Human Development in Nigeria. J Mass Communicat Journalism 4: 224. doi:10.4172/21657912.1000224

Copyright: (c) 2014 Nwanne BU. This is an open-access article distributed under the terms of the Creative Commons Attribution License, which permits unrestricted use, distribution, and reproduction in any medium, provided the original author and source are credited. 
and ultimately affects, the state of media practice in that environment. Ethics of journalism would suggest the internal mechanism in journalism, which enables the journalist determine that certain actions or inactions are right or wrong and would therefore retard or advance the practice of journalism [3]. It is expected that since ethics are 'self imposed', the journalist would do well to abide by them. One of such issues is the recognition and protection of the right of the individual to privacy, which is the focus of this work.

\section{New media}

According to McQuail [4] new media are disparate forms of communication technologies that share certain features apart from being new, made possible by digitalization and being widely available for personal use as communication devices [5]. Olise [6] sees new media as "Information And Communication Technologies (ICTs) and their associated social contexts, incorporating the artifacts or devices that enable and extend our abilities or practices engaged in, to develop and use the devices; and the social arrangements or organisations that form around the devices and practices". The new media suggests all the gadgets, means, avenues or opportunities of enhanced communication. New media are built around computer capabilities (microprocessors or mainframe) that allow or facilitate interactivity among users or between users.

\section{Development}

Development is the perpetual concern in any human setting. Not unexpectedly, therefore, development has different dimensions. Amucheazi [7] sees development as a "multi-dimensional process involving the totality of man in his political, economic, psychological, social relations, among others". The Guyanese Scholar, Rodney [8] describes development at the individual level to imply "increased skill and capacity, greater freedom and creativity, self-discipline, responsibility and material wellbeing". In all, development may be seen as a well thought out and self-sustaining effort aimed at achieving a higher level of economic, cultural and psychological improvement and other desirable indices of progress [9].

\section{Theoretical Framework}

Theories drive practice, hence the need to articulate a theoretical framework appropriate for this paper. According to Kelinger [10] a theory is "a set of interrelated constructs (concepts), definitions and propositions that present a systematic view of phenomena by specifying relations among variables, with the purpose of explaining the phenomena".

The social responsibility theory provides anchor for this paper. The idea of social responsibility is an offshoot of the libertarian theory, one of the normative four theories of the press. The theory espouses the view that while the press should be free to carry out its obligations to society, it must, in return, be responsible in protecting societal values, ethos and norms. In other words, the media, while enjoying freedom, must be cognizant of its obligations to society.

The social responsibility media theory began to take roots in the United States of America (USA) following the setting up of the Hutchins Commission on freedom of the press in 1947. In any case, the USA has always had a largely free press due to the libertarian environment created by its leaders over the years. Even the American constitution supports an unfettered press. According to the first amendment of the US constitution "Congress shall make no laws abridging the feed one of the press". According to Folarin [11] the social responsibility theory canvasses the freedom of the press, adding that it assigns six functions to the press to include:

- Serving the political system by making information, discussion and consideration of public affairs generally accessible.

- Informing the public to enable it to take self determined action

- Protecting the rights of the individual by acting as watch dog over the government

- Serving the economic system, for instance, by bringing together buyers and sellers through the medium of advertising

- Providing good entertainment, whatever good may mean in the culture at any point in time.

- Preserving financial autonomy in order to be become dependent on special interests and influences.

Essentially, the idea of social responsibility is built on the fact that the media institution must be free from unnecessary government interference to carry out its duty to the society. However, in doing this, it must be fully cognizant of its responsibilities to the state as well as well as obey all laws enacted for its good and orderly governance.

\section{Journalism in the Era of New Media}

Journalism, as those who are actively involved in it know, is an exciting but exerting job. But for those outside, there is a tendency to see more of the excitement. That is perfectly all right for the reader or viewer of the mass media products. However, for the practicing journalist or those in training, it is realistic to appreciate the physical, mental, psychological financial and emotional exertions often associated with the job especially in developing or emerging economies, largely because many media houses do not have adequate facilities. The most modern printing technologies are probably out of reach as a result of financial constraints. Physical impediments remain a clear and present danger as journalists are still assaulted in the course of carrying out their legitimate business. In fact, many have been killed in the course of doing their jobs.

In 2011, Nigeria lost a Channels Television reporter in Kano. He was a victim of the Boko Haram sect, an insurgent militant group in Northern Nigeria which abhors anything "Western". Despite the challenges, it is obvious that many journalists are gradually embracing the new media technologies in the performance of their duties, to the mutual benefit of their media organizations and their readers/viewers.

This fact was attested to by Olise [6] when he observed that: It is no longer news that journalists in Nigeria have started embracing the new media for journalism practice. This is not surprising especially with the fact that they are living in the new information and communication world. Nigerian journalists employ the use of various new media to improve journalism practice. Some of these new media are the internet, e-mail, video conferencing, mobile phone, DVD, CD-ROM, microcomputer, among a host of others.

Although many have argued, with more than a grain of truth, that the ICTs have enhanced interdependence, but it has widened the gap between the rich Western nations and the poor countries of the South.

According to Alozie [12]: ICTs force the world to become increasingly interdependent, it is also creating a wider economic gap between the North and South. These technologies are being used to convey Western software, such as advertising music, news, and TV programmes, into Africa without reciprocal exchanges. This imbalance, coupled with the 
hegemony of global capitalism has compelled activists to voice their opposition (CNN.com 2001). During the 1990s, these peaceful as well as violent protests in the major cities of Asia, South America, Africa, North America and Europe to protest globalization, capitalism and rapid technological advances.

Despite the seeming political economic and even cultural disadvantages of the new media, it is not in doubt that ICTs have been of immense benefit to journalists in developing countries, especially in Nigeria. It might therefore be necessary at this point to discuss the new media, one after the other, with a view to exposing or explaining their potentials for enhancing journalism practice.

\section{E-mail}

The electronic mail is an invaluable introduction in Nigeria's communication arena. It got to a point where many residents did not even know of the existence of a post office around them. Mails took weeks or even months to move within the country, thereby destroying the confidence in the system. So slow were the mails that they are now known as "snail mails". The private sector cashed in on it and introduced courier services at exorbitant costs. However, with the introduction of the e-mail, many heaved a sigh of relief. The journalists were perhaps the greatest beneficiaries as heir stories could get to the news room just in seconds. This enhances productivity of the reporter and the production process of the media organisation.

\section{Internet}

Perhaps the most outstanding invention in the ICT segment of communication is the internet. Baran [13] describes the internet "as a global network of interconnected computers that communicate freely, share and exchange information. According to Amobi [14] the "internet continues to be a buzz wood as young peoples lives increasingly appear to be inextricably woven to this new media".

Amobi further states that: Studies from 2008 to 2011 indicate an unprecedented increase in internet usage population in Nigeria, from 1,129,345 in 2008 to over 44,000,000 in 2011, and more than half of them are believed to be young people. Nigeria has also been rated the country with the highest number of internet users in Africa, with Egypt and Morocco coming a distant second and third with 20 million and 13 million users respectively.

From the figures above, it must be taken for granted that journalists constitute a reasonable percentage of internet users since theirs is professionally imperative. In fact, that perhaps explains Olise's [6] insistence that "it is practically impossible to talk about writing news for the new media without talking about the internet". He, however, observes that before a journalist can use the internet for journalism practice, he/she must first and foremost have access to all the internet connections required. This can be done by getting connected through a Local Area Network (LAN), through a computer or though the Internet Service Provider (ISP).

The journalist lives on disclosure, but he/she can only disclose information available at the time of going to press or going on air. The internet provides a huge mine of information about events, places and individuals than can be made interesting to readers, listeners or viewers. Besides, it facilitates interviewing as the reporter can use it to elicit information from potential news sources. This does not in any way relieve the journalist of his/her news gathering role. It is an invaluable facilitator in the task of news gathering.

\section{Video conferencing}

Satellite technology, a modern technology of immense value, has made video conferencing possible. Essentially, video conferencing enables different audiences scattered all over the world to talk and see one another from their different locations. For the journalist this is a great advantage as he/she is able to obtain immediately information on an event taking place thousands of kilometers away. For quite sometime, media organizations in advanced countries have been availing themselves of this technology. The Cable News Network (CNN) which prides itself as "the world's news leaders' has been using the satellite technology to obtain news from distances ordinarily considered to be very far off. That explains why CNN's Aisha Sesay speaks with correspondents across the world with their pictures displayed on the screen as they speak.

\section{GSM}

The Global System for Mobile communication, GSM for short which was introduced in Nigeria in 2001, with Econet being the first, is perhaps the most widespread piece of the new media on account of its relative affordability and amenability to the vagaries of electricity power.

Empirical research at Businessday online shows that of the one hundred and fifteen Million mobile telephone subscribers in the country 35 million use of the their hand held devices to access internet data services. Projecting into the future, the research discloses that Nigeria will remain the largest internet users on the continent in the near future because it has a large youth population (One third of the population is between 10-24 years age bracket), a growing middle class estimated at $23 \%$ (approximately 39 million).

Once charged, a GSM phone may last for about 48 hours deepening, of course, on usage. Such a piece of new technology can be easily used by the journalist, who is always on the look-out for what is new and interesting to his readers, listeners or viewers. The GSM telephone is useful for conducting news interviews as they are not usually lengthy. If possible, feature interviews are better conducted "live" with the subject. This is to enable the interviewer observe the environment, the subject (his style of speaking, his mannerism, idiosyncrasies and other interesting aspects). The reporter may also wish to phone-in his/her story as that would make it faster and easier for as long as the network is 'faithful'. This is preferable to attempting to rush to the newsroom with an important story which might be futile as a result of heavy traffic in such a city as Lagos, Nigeria, or crashing another car by over speeding or/and reckless driving in an effort to beat a deadline.

\section{Microcomputers}

Olise [6] leaning on Williams and Sawyer, notes that microcomputers, or personal computers, are either stand alone machines or are connected to a computer network such as Local Area Network (LAN). For the journalist, who is computer savvy, the microcomputers must be of inestimable value.

As Okoye has observed: Now the entire editorial process prior to printing, including writing of text, editing to form, content and length; typesetting of copy of making-up the page with text headlines, pictures and graphics; and producing negatives could be done on the computer.

With the obvious advantages of digital communication, which the new media represent, journalists can now do much better at their jobs as news gathering, processing and packaging have been made much easier and faster. 


\section{The Right to Privacy}

Journalism is a public service that permits its practitioners to write and publish information about groups, governments and individuals. This places a high degree of responsibility on journalists. As Nwanne [3] has observed: Journalism is not a job for men and women who have no respect for the hard earned reputation of their fellow countrymen and women. Rather, it is a profession for sobre and mature people who would act in the interest of society as a whole by treating every story with fairness and, of course, by obeying the laws that affect media practice.

It is a universal fact that news is all about human beings- their activities, actions, inactions, mistakes, foibles, achievements and others. However, in reporting these activities, the reporter must show a high level of professionalism and introspection so that an individual's reputation is not needlessly destroyed or his/her privacy unnecessarily invaded. This is because every individual deserves a measure of privacy, depending on the level of intimacy he/she has with other members of society. A person whose privacy is recklessly invaded is empty and even naked. This affects his/her mental and emotional stability, with negative consequences on his reasoning and by extension, productivity. Such a person is often not in a position to meaningfully contribute to natural development efforts.

Of Concern to many is the careless use of personal information often provided by internet users. According to Consumer Report 2010 State of the Net Analysis, more than half of social network users share private information about themselves online opening themselves to a variety of online dangers.

The need to protect the privacy of an individual has been widely acknowledged, perhaps all over the world, except in authoritarian regimes. The Code of Ethics for Nigerian Journalist [15] draws attention to the need to protect the privacy of an individual in the following words: As a general rule, a journalist should respect the privacy of individuals and their families unless it affects public interest

- Information on the private life of an individual or his family should only be published if it impinges on public interest

- Publishing of such information about an individual as mentioned above should be deemed justifiable only if it is directed at;

- Exposing crime or serious misdemeanor;

- Exposing anti-social conduct;

- Protecting public health, morality and safety;

- Preventing the public from being misled by some statement or action of the individual concerned.

The above code of ethics clearly shows that the individual deserves privacy in his/her every activity but also provides the circumstances under which such protection could be vitiated or annulled. For instance, an armed robber, having shattered social harmony and caused perhaps bodily harm or economic adversity, loses his right to privacy, as he/she is paraded before television cameras. Even if such a person seeks legal protection, it is unlikely that he/she would have any legal reprieve.

\section{Invasion of Privacy: Case Studies}

In the following pages, the author articulates the important role of ethics in journalism. However, in an effort to publish the elusive scoops, editors and reporters at times become desperate to obtain "hot" news at all costs. In some cases, even the editor-in-chief or publisher is involved in the chase. Most of the time the need to draw attention to a publication and then rapidly increase sales and profitability are the driving forces for such ethical breaches. The author presents some case studies in invasion of privacy.

\section{The sir rupert murdoch case}

Sometime in 2011, a great ethical violation occurred in the United Kingdom which is often seen as one of the "headquarters" of journalism practice in the world, with its flourishing Fleet Street, London. But that was not so as one of the world's most popular publishers, Sir Keith Rupert Murdoch and his son, James, owners and operators of News of the World and other publications got involved in a big scandal which shook the international media world to its very foundations. As Nwanne [16] has observed: the ethical breach was about the violation of people's privacy, via phone hacking. The issue was so serious that the accused had to face the Culture and Heritage Select Committee of the British Parliament to answer questions on the activities of the Murdoch media groups.

Essentially, the fact that the Murdoch incident drew the attention of the public and even the Parliament reflects the sensitivity of British Government to issues of individual rights. The fact that Murdoch was summoned before Parliament and appropriately reprimanded suggests that virtually nobody could take everyone for granted all the time in the United Kingdom or anywhere else.

A Special Report published in one of Nigeria's National Papers, Vanguard [17] gave details of the incident, expanding that: The media world became tensed up following the report of hacking the phones of people as news sources including crime victims and those who are dead, ostensibly by journalists in The News of the World, one of the titles in the Murdoch stable. The disclosure led to the closure of the offending 168year old newspaper. The incident also led to the resignation of Brooks, and her arrest and interrogation by the police, the exit of the London Police Boss, Mr. Paul Stevenson while the alleged whistle blower died in mysterious circumstances.

The Murdoch saga must be one of the most news worthy developments as far as the invasion of privacy is concerned on account of the personalities involved in a great newspaper which had been on the news stands for almost 170 years. This raises the question of integrity in the mass media. Does it also suggest that the media empire had previously been involved in such unethical practice? The incident draws attention to the issue of social responsibility of the media to the society. But in violating the privacy of the individual, Murdoch and his group had put their selfish financial interests over and above the interest of society by violating the right to privacy of the individual. Nwanne [16] puts the issue in proper perspective by his observation that "while admitting that the media must survive financially for them to be in a position to promote and defend societal values and aspirations, there is probably no iota of doubt that the media should conform to ethical and societal aspirations".

\section{The anita hogan incident}

One of the cases of invasion of privacy which occurred in Nigeria took place in the country's former capital and financial hub, Lagos. Apparently to sell their paper, the editors of $P M$ News, an afternoon paper, splashed the nude photograph of a female actress, Anita Hogan, on its front page. The salacious photograph naturally elicited different reactions from different quarters. Some were of the opinion that the newspaper had the right to publish any material it is able to unearth in exercising its freedom of the press while another school of thought 
believed the lady's privacy had been mindlessly invaded. The former school of thought rests its case on the unhindered right of the press to publish whatever is not explicitly forbidden by the law, while the other school of thought believes that every Nigerian had a right to their privacy which people guard jealously. They rest their case on section 37 of the 1999 constitution of the Federal Republic of Nigeria [18] which guarantees and protects "the privacy of citizens, their homes, correspondence telephone conversations and telegraphic communications".

Another issue of interest was the method of obtaining the information. Ordinarily, one would have thought that within a "moment of madness" the actress had decided to bare it all for whatever reasons. However, that was not the case, as was later revealed. According to the victim, the "offending" photograph was obtained from a laptop which she had sent for repairs. If this is anything to go by, professional journalists and legal authorities would wonder whether the method of obtaining the information was ethical or not. Some have also raised the question of the veracity of the victims account because it would be 'unsafe' to store one's nude photograph in a laptop, given the possibility of falling into the hands of a third party. The opposing argument, of course, is that the victim has the right to store any photopgraph anywhere as it is all part of her privacy. On the part of the journalists it would be needless asking for their source of information, as journalists do not usually reveal the sources of their information in situations such as this one.

\section{The oge okoye photo-shoot}

This particular indent deals with the publication of absence materials; which also gives the impression that someone's privacy has been tampered with. Oge Okoye is a popular Nigeria actress who has participated in many Nollywood films.

According to a human interest magazine, City People [19]: When the light-skinned actress decided to do a photoshoot with a different and unique concept, little did the mother of two know that the creatively conceived photo session tagged "Time" would generate a negative response from fans.... Since the photo speak film...shot by Mousa Moussa and directed by Egor Efiok was released online, the social media has (sic) been awash with countless unsavory comment about the shoot, with a lot of people criticizing the actress for the crudity which she displayed in them.....

The magazine elucidated the content of the photo-shoot thus: some pictures from the shoot had a bedroom scene where the actress who was dressed in sexy outfit, struck different poses with a man sparingly dressed. In some pictures, the white skinned man was garbed in men's underwear as both cut the picture of two lovers in a wild romantic rendezvous. Pictures elicited negative comments and remains from different social media.

Unlike in the two previous cases where the victims of invasion of privacy could not have been said to have contributed to their travails, the Oge Okoye saga tends to suggest that the star actors could not have been the victim since the idea, according to City People [19], was hers. She obviously conceded part of her privacy to an audience which did not seem to savour it, largely due to a culture of discreteness with matters of privacy in Nigeria. Since she was part of the entire plot to expose part of her privacy she could not therefore complain. This finds anchor in the legal concept of velonti non fit injuria, roughly translated to mean in this context that you cannot complain about an idea upon which you actively participated in its conceptualization and execution.

\section{Challenges of New Media Use}

A cursory observation would reveal that there is an increase in access and use of the new media among professional journalists and non-journalists. This is understandable, given the pervasive nature of the new media. Despite the improvement in the use of the 'technological wonders', it is also obvious that they are not being accessed as much as they should, given some challenges that tend to limit their use.

\section{High cost}

New media are sophisticated pieces of technology. That invariably means high cost of the equipment which many persons, including professional journalists, may be unable to afford. Indeed, the GSM which many persons can afford, have different categories. For instance, the cheaper ones are not internet enabled, thus limiting their utility.

\section{Poor power situation}

One of the most disturbing issues in Nigeria is the absence of stable power. This situation has tremendous impact on the economy. Lack of adequate power supply has detrimentally affected the country's industrial take off. Many small and medium scale factories have died a natural death as a result of the poor power situation, while some well established companies have relocated to neighbouring countries that have better electricity situation. The voluble ex-president of Nigeria, Olusegun Obasanjo, while in power, was reported to have spent billions of dollars in an effort to improve power supply, without much success. The current President, Dr. Goodluck Jonathan, made the issue of improved electricity a sing song during campaigns and at the beginning of his administration. There is no evidence to suggest that Jonathan has left the stage of rhetorics so far.

\section{Lack of Knowledge and Skill}

Given that the new media are pieces of sophisticated equipment, it follows that using them also requires a measure of sophistication and high skill. The acquisition of knowledge and skill is invariably linked to the level of literacy in any economy. But unfortunately, literacy level is painfully low in Nigeria. In fact, the sight of a piece of state-of-the-art new medium can be frightening to an illiterate person! So the question of operating it is practically out of the question. On the part of the professional journalists, many do not make themselves available for computer training and appreciation with the result that their ability to operate the new media is impaired in important ways.

\section{Summary and Conclusion}

In the past few decades, there has been an explosion in human knowledge and communication, fulfilling an earlier prediction by media iconoclast and thinker Marshal McLuhan of an imminent "global village". The explosion seems to have taken place more with the internet which has revolutionized access to knowledge and information.

In order to attain a measure of conceptual and operational clarity, such terms as media laws, new media and development have been defined. Also, a theoretical framework, social responsibility theory, has been articulated to explain the idea of balancing freedom to perform certain media roles and societal expectations and values.

No doubt, journalism practice in the era of new media has become more sophisticated, requiring a high level of knowledge and technological savvy represented by the new media. The new media in use in Nigeria include but not limited to e-mail, internet, video conferencing, GSM and microcomputers. 
Citation: Nwanne BU (2014) The Right to Privacy, The New Media and Human Development in Nigeria. J Mass Communicat Journalism 4: 224. doi:10.4172/2165-7912.1000224

The need for the guarantee and protection of people's privacy has also been stressed, as this is in tandem with the provisions of section 37 of the Constitution of the Federal Republic of Nigeria [18] and the Code of Ethics for Nigerian Journalists.

Despite the acknowledged need to respect the privacy of individuals, there have been cases of abuse or non-challenge to people's right to privacy such as the Sir Rupert Murdoch incident in the United Kingdom, where reporters hacked phone lines and other devices to obtain information illegally; the publication of the nude photographs of a Nigerian actress, Anita Hogan, and the publication on facebook of the nude photograph of another Nigerian actress Oge Okoye, which has elicited widespread condemnation in Nigeria. The search for the penetration of the new media is vitiated in important ways by such challenges as poor power situation, high cost, lack of knowledge and skill and so on.

It is expected that in the years to come Nigeria would be in a better position to address some of the daunting challenges that tend to limit access, penetration and use of the new media. In doing this, however, the right to the privacy of the individual should be recognized and respected as any situation to the contrary would hurt the individual and limit his/her ability to contribute to national development.

\section{Recommendations}

In view of the foregoing, the following recommendations are being put forward for consideration and possible adoption by relevant authorities and those concerned.

- Computer education should be encouraged in practical ways. The current situation where those in authority speak of the need for computer education of the citizens without taking practical steps to achieve it is not useful. Rather, a well conceived programme which should should be put in place and faithfully implemented so that Nigerians are exposed to computer technology from very early in life.

- Ethical orientation should be take seriously in the country with journalists and other persons. For some reasons yet to be deciphered, it would seem that ethical issues have been pushed to the background in the country, with the result that many issues are handled haphazardly and, often, corruptly. It is expectedly that over the years, Nigeria is likely to become an ethical "bread basket" of Africa. Indeed, with a sound ethical background, the need to violate the privacy of another citizen would be reduced to the barest minimum.

- Apart from institutional effort at acquiring and improving knowledge and skill in operating the new media of communication, there is also an overriding need for personal effort in this regard. A personal regime of computer education and appreciation would be highly useful in this regard, as constant and dedicated exposure to these "magic" gadgets would definitely enhance competence.

- Media houses should do much more than they are doing at the moment by investing more in the acquisition of the new media as well as encourage their staff to spend quality time in learning how to use them.

- It is recommended that the poor power situation in the country should be addressed. Efforts should be intensified to generate electricity given the large population of the country. The fruits of the privatization of the power sector, touted as being the panacea to the problem, as still being eagerly awaited.

- Since the use of the new media can be enhanced by a higher literacy level, Nigeria must wake up to the need to quickly embrace mass literacy campaign to improve its literacy level which is currently low.

\section{References}

1. Amobi IT (2011) Assessing Global Digital Divide through computer, literacy, access and usage of New Media by Nigeria Youths. In Communication Review.

2. Mobile phones now primary access to internet in Nigeria. Sunday Vanguard.

3. Nwanne BU (2008) Essentials of News Reporting and Writing. Lagos: Broada Publications.

4. McQuail D (2005) McQuail's Mass Communication Theory. Los Angeles CA: Sage.

5. Leivrouw LA, Livingstone (2006) Introduction to the First Education (2002). The Social Shaping and Consequences of ICTs. In The Handbook of New Media. Updated Student Edition. London: Sage.

6. Olise FP (2010) News Writing for the New Media: An Insight for the Nigerian Journalist. In Nigerian Stirling-HordenEncyclopeadia of Mass Media and Communication. Technological Imperatives. Ibadan: Stirling-Horden.

7. Amucheazi EC (1980) Readings in Social Sciences: Issues in National Development. Enugu: Fourth Dimension Publishers.

8. Rodney W (1973) How Europe Underdeveloped Africa. London: Bogle Ouverture Publications.

9. Nwanne BU (2006) Communication, Leadership and National Development. In African Journalism and Communication Review.

10. Kelinger FN (1973) Foundations of Behavioural Research. (3 $3^{\text {rd }}$ edn). New York: Holt, Rinehart and Winston Inc.

11. Folarin B (2002) Theories of Mass Communication: An Introductory Text. Abeokuta. Link Publication.

12. Alozie EC (2010) The Digital Divide and Status of Sub-Saharan Africa: The Role of Information and Communication Technologies in National Development and Marketing in an Interdependent Global Economy. In Mass Communication: A Book of Readings. Lagos: Department of Mass Communication. Unilag.

13. Baran S (2004) Introduction to Mass Communication: Media Literacy and Culture. ( $3^{\text {rd }}$ edn). Boston: McGraw-Hill.

14. Amobi I (2010) Paradigm Shifts in Mass Communication Theories: An Argumen for Change in Paradigm. In Mass Communication: A Book of Readings: Lagos: Department of Mass Communication, Unilag.

15. Nigeria Code: Code of Ethics for Nigerian Journalists (1998) The Nigerian Press Council.

16. Nwanne BU (2012) Media Laws and Ethics in Multicultural Nigerian Environment. In The Media, Terrorism and Political Communication in Nigeria Uyo: ACCE, Nigeria.

17. Odiogor H (2011) Rupert Murdoch: Media Power and Politics. Sunday Vanguard.

18. Constitution of the Federal Republic of Nigeria 1999

19. City People, February 13, 2013. 